\title{
THE AWARENESS OF ALLIED HEALTH PROFESSIONALS REGARDING ROLE OF PHYSICAL THERAPY IN IN-PATIENT \\ SETTING
}

\section{ABSTRACT}

\section{BACKGROUND AND AIMS}

In order to deliver effective treatment, the awareness of physical therapy is essential for the health care professionals. However, there is lack of cognizance among Allied Health Professionals who play a substantial contribution to patient care. Thus, the aim of conducting this study is to explore the perception about the field of physical therapy among Allied Health Professionals that may lead to improved health-related outcomes of the patients consequently increasing their quality of life.

\section{METHODOLOGY}

The cross-sectional survey was conducted on Allied Health Professionals, recruited through the non-probability convenience sampling technique. The data was collected through self-administered questionnaire.

\section{RESULTS}

It was revealed that $95 \%$ of the participants were aware about physiotherapy and its importance, $85.6 \%$ suggested that awareness session for physiotherapy should be conducted for medical professionals, $87.3 \%$ were eager to encourage their friends and family to choose the profession as physiotherapist. Further, $83.5 \%$ think that physiotherapist contributes to the well-being of individuals, $85.6 \%$ were willing to have physiotherapy. However, $20 \%$ were not interested in physiotherapy and related discussion.

\section{CONCLUSION}

It was concluded that majority of the participants were aware regarding the role of physiotherapy and its contribution towards the society. However, further researches should be conducted to explore the awareness related to different fields of rehabilitation among healthcare practitioners.

\section{KEYWORDS}

Physiotherapy, Allied Health Professionals, Healthcare Workers, Delivery, Patient-care, Awareness.
Syed Hasan Abbas Rizvi Principal

Liaquat National School of Physiotherapy

Email id
[Rizvi SHR. The Awareness Of Allied Health Professionals Regarding Role Of Physical Therapy In In-Patient Setting.Pak.J Rehabil.2021:10(1):106114]

DOI; 10.36283/pjr.zu.10.1/014 


\section{INTRODUCTION}

Doctors have great impact on health practitioners including physiotherapists as they are the highly efficacious. The act of endorsing physiotherapy by most doctors has been giving incredible importance to physiotherapists around the World. According to Chartered Society of Physiotherapy it is a profession which applies various techniques and procedures to improve person's quality of life ${ }^{1}$. Physical therapy is one of the wide fields of allied health sciences, having treatments for acute or chronic pain, injuries or other physical impairments. Physical therapists are highly skilled professionals, treating wide spectrum of physiological health issues. Primarily it plays a key role in aiding the individuals who have lost their mobility and in turn suffer from disorders related to movement ${ }^{2}$. In addition to it, it plays essential role in treatment of various disorders, such as decreasing different types of depression, cancer, reducing weight, limiting chances of developing risk of type 2 diabetes mellitus and CVDs. However, some of its effects are still questionable $^{3}$. According to $\mathrm{WHO}$, for every 10,000 people of this world there should be one physiotherapist assigned ${ }^{3}$. Physiotherapy has a number of broad ranges of proficiencies application which are mobilization techniques, electrotherapy, manual therapy and others, which can be used for prevention and rehabilitation of various disorders by augmenting movement potential and functioning ${ }^{4}$. Furthermore, in 1999, the World Confederation for Physical Therapy (WCPT) acquired prevalent explanation of physiotherapy worldwide. It expresses that physiotherapy gives treatments to people to increase their functional abilities in every stage of their life ${ }^{5}$. Physical therapists prevent the development of complications, hospital stays could be decreased to a larger extent if the physician had knowledge of how well physiotherapist has ability to treat patients ${ }^{5}$.

Professional growth in the field of physical rehabilitation can only be achieved by support from fellow healthcare practitioners, who needs to learn about the role of PT professionals first in order to promote awareness ${ }^{5}$. Since patient care is not a single entity, it needs collaboration and support of a team as a whole that work together as one unit to promote wellbeing of the patient and to make prognosis even better. Physical therapy has come a long way over the years ${ }^{4}$. In most countries, access to primary health care is a basic right therefore every individual should also have access to physiotherapy service as it the part of the primary health care and is now practiced extensively in all these communities ${ }^{6}$. Physical therapist can play an effective role in patient handling and well-being of individuals, provided the opportunity, which is only possible if the other health care professionals are willing to provide collaboration. In 2015 a review was conducted regarding the awareness of physical therapy around the world which concluded that literature related to awareness of physical therapy was very limited in health care system and the need for awareness of physical therapy as a profession was very urgent to improve functional outcome ${ }^{3}$. Physical therapist not only can help to improve the wellbeing of the patient but also they can work for betterment of other health care professionals by educating them on practicing postural awareness and correction. As observed, dentists are at an increased risk of various musculoskeletal disorders and those who obtained guidance from physical therapist regarding ergonomics has seen decline in this problem ${ }^{8}$. Nonetheless, one of the 
major setbacks experienced by physical therapist in referrals is limited knowledge of the field of physical therapy and also reluctance of professionals to explore ${ }^{9}$. The main aim of the study is to explore the awareness among the various health care professionals regarding the field of physiotherapy and the role it can play to improve the overall health of the patient. Furthermore, it also aims to investigate the importance of the perception of the workers in the different fields of medicine regarding this mode of treatment since their knowledge is quite essential so that they can refer the patients to get benefit from the physical mode of treatment.

\section{OPERATIONAL DEFINITION}

\section{ALLIED HEALTH PROFESSIONALS}

Allied health professions working in health care setting including nutritionists and dietitians and physician assistants, audiologists, diagnostic medical personnel (anesthesia technician, medical laboratory scientist's diagnostic, molecular scientists, and pathologists, histo-technologists) and speech language pathologists imaging specialists (nuclear medicine technologists, radiographers, and sonographers) which are all non-physician health care providers.

\section{PHYSICAL THERAPY}

It refers to a branch of rehabilitative health that is designed to implement specific exercise using either equipment or manual techniques to improve the health status of a patient and improve his quality of life.

\section{AWARENESS}

In our study awareness refers to the knowledge regarding the general and specific services provided by physical therapist. Furthermore, the specific role played by physical therapist, and the importance of physical therapy in the process of rehabilitation.

\section{METHODOLOGY}

Study Setting: Data was collected from rehabilitation department of tertiary care hospital i.e. Dr. Ziauddin Hospital, Clifton and North respectively.

Target Population: Allied Health Professions.

Study Design: Cross-sectional Study.

Duration of Study: 6 months

Sample Size: The sample was calculated using online software Open EPI, open source calculator version 3.01. Therefore, at 100000 populations with $50 \%$ of anticipated frequency, a sample of 196 was calculated at $95 \% \mathrm{Cl}$ and $7 \%$ bound of error. Non-probability Convenience Sampling Technique.

\section{Sample Selection}

\section{Inclusion Criteria}

- $\quad$ Allied health professionals including Clinical Laboratory Workers, Medical Technologist, Emergency Medical Technicians, Health Administration, Orthotic and Prosthetic Technician, Speech -Language Therapists working in in-patient setting.

- $\quad$ Allied Health Professionals who voluntarily agreed to participate.

Exclusion Criteria

- General practitioners including PGs and interns, Nursing staff, Physical therapist, Surgeons.

- Unwilling subjects and subjects not related to medical field.

Data Collection Tool: The data was collected from self-administered questionnaire that consisted of two sections, comprised of demographics of participants and questions regarding awareness of physical therapy in inpatient setting. A total of 17 questions based on awareness of physical therapy, its course, degree programs, its role and 
contribution towards well-being of society were obtained on a dichotomous 'Yes' and 'No' scale.

Data Collection Procedure: Data was collected from a rehabilitation department of a tertiary care hospital of Karachi. Participants were recruited as sample on the basis of inclusion criteria. Prior to the data collection, all participants were provided with informed consent in order to have detailed information about the study. Followed by the consent, participants were given selfadministered questionnaire to record their responses regarding awareness of physical therapy. After the data collection, responses were analyzed to infer the perception of Allied Health Professionals towards physical therapy.

Data Analysis: Data was entered and analyzed on SPSS (Statistical Package for Social Sciences). Participant's demographic details were represented through descriptive statistics using mean and standard deviation whereas participant's responses were represented through frequency and percentage.

Informed consent was taken from each participant. Participants were given the right to withdraw from the study. Moreover, adequate level of privacy of the research data was guaranteed and confidentiality of participants and organizations taking part in the research was ensured.

\section{RESULTS}

A total number of 196 responses were obtained in which $55 \%$ were female and $45 \%$ were male with the mean age of $28.1 \pm 4.5$, practicing for about average of $5.8 \pm 4.1$ years. Out of $100 \%, 96 \%$ of the participants were aware about physiotherapy whereas, $4 \%$ were unaware about it. Fig 1 summaries the different sources of awareness regarding the field of physiotherapy, where $41 \%$ individuals came to know about physical therapy through hospitals and medical centers, $32.40 \%$ came to know during their graduate studies, $15 \%$ came to know through word of mouth, $5.80 \%$ came to know through mass media, and the rest $1.40 \%$ came to now through their colleagues. Furthermore, the awareness about respective physical therapy subdomains was also evaluated. Where $70 \%$ of the individuals were aware about the role of physical therapist in managing neurological patients, $69 \%$ were aware of physical therapist role in managing sports injuries, 64\% were aware about a physical therapist's role in ICU, 58\% were aware about the post-surgical role of a physical therapist in orthopedic rehabilitation, $41 \%$ were aware about the geriatric rehabilitation related role of a PT, $36 \%$ were aware that a Physical therapist can suggest an orthosis, and $27 \%$ were aware about their role in managing burn patients. (Fig 2).

In addition to it (85.6\%) participants think that physiotherapy should be available in all hospital, while $61.90 \%$ thinks that physiotherapists have very important contribution towards society, whereas $(83.5 \%)$ thinks that physiotherapist contribute to the well-being of individuals who seek their services, whereas (84.2\%) individuals recommends different physiotherapy services and (87.8\%) encourage their family member/friends to become a Physiotherapist.

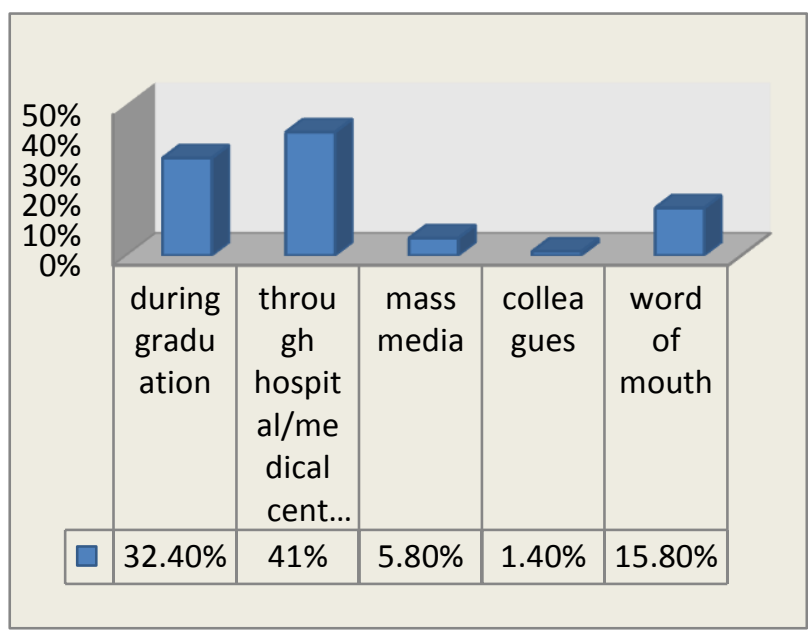

This is an open-access article distributed under the terms of the Creative Commons Attribution License (CC BY) 4.0 
Figure 1: Awareness of physical therapy through different sources
Patients for Physical therapy by Doctors" found that, in Nigeria, physical therapy is used on a consultation basis as a

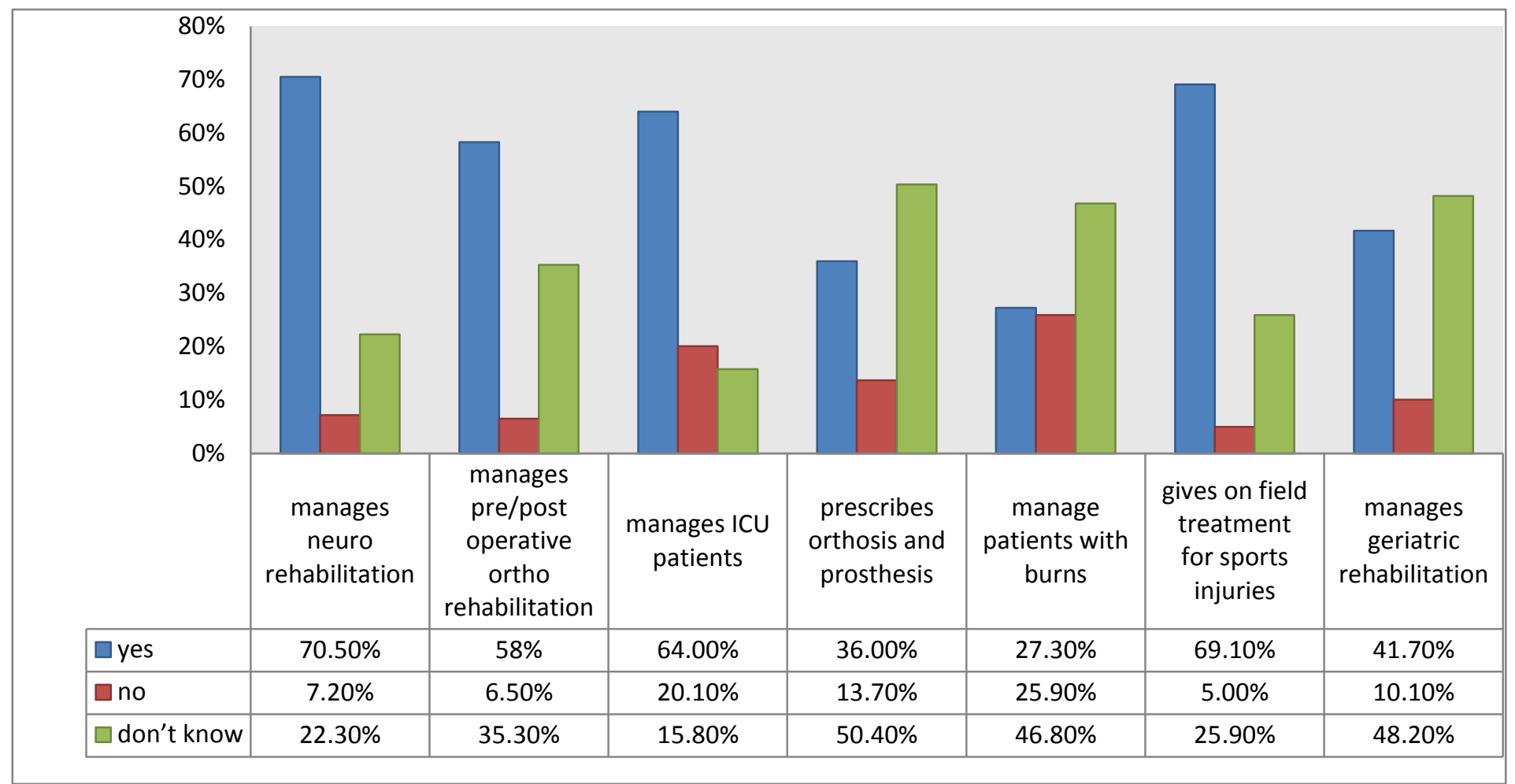

prescription rather than a reference. The

Figure 2 - Role of Physiotherapists in patient management

\section{DISCUSSION}

The study was conducted with primary aim to understand the perception of Allied health professionals towards the profession of physical therapy in the inpatient setting. Many Allied health practitioners were being approached but only 139 respondents were willing to participate in this study. This study concluded that majority of the health care professionals are aware about the role of physical therapy in wellbeing and over-all quality of life of the patients. Nonetheless, it was also observed that there is a lacking in overall referral of the patient to the physiotherapists which can be attributed to the carelessness on the part of health care team.

Moffatt F. et al., 2018 in their study "Assessment of the Mode of Referral of research found that $88.4 \%$ of physicians agreed that physical therapists could make clinical decisions based on their skills and $56.9 \%$ refer their patients to physical therapists. This study is in accordance with our findings where majority of the physicians have showed that they have prior knowledge of physiotherapy ${ }^{9}$.

Alshewaier et al (2018), concluded that physical therapy as a profession is well known as an independent profession in Riyadh. This shows that physical therapy is playing major role in patient's prognosis and prevention in Riyadh which is providing better quality of life ${ }^{7}$. Continual training sessions for a new field are the future ${ }^{10}$. We need to implement continual training sessions for the various health care professionals in Pakistan as well. This practice will enable them to understand the efficacy of this particular 
treatment and more patients will be benefited from this treatment.

Sarikaya et al, focused on the awareness of allied health professionals regarding cardiopulmonary rehabilitation. The results of the study reported attenuated awareness of the professionals and claimed a nationwide poor rate of awareness and knowledge of cardiopulmonary rehab ${ }^{11}$.

Levenhagen K, et al 2017 in their study proposed that physical therapy is indicated as important factor in rehabilitation of patients after surgery. This study concluded that physical therapy can reduce lymphedema which is the major complication and makes a lot of difference in the QOL of patients with breast cancer after surgery ${ }^{12}$ Lymphedema is a serious complication of various disorders specially the partial or complete mastectomy which leads to debilitating life conditions. Physiotherapy can be method of choice for such patients since it improves the physical symptoms, reduce the impairment and thus leads to improved functioning by incorporating techniques such as massage, compression bandaging and active exercises to the therapy ${ }^{13}$.

Khedekar S, et al. 2017 conducted a pilot study in India were surveys with respect to significance of physiotherapy in rheumatoid arthritis patients was conducted. The results showed that $90 \%$ showed positive response regarding physical activity of patients to decrease pain and increase QOL. Rheumatoid arthritis severely limits the functioning capacity of the patient to an extent of disability. The physical mode of treatments along with the medicine can slow down the progression of the disease and improve the symptoms thus enabling the patient to actively participate in mainstream functional requirements ${ }^{14}$. Despite the fact that reviews guarantee that overall experts in India know about physiotherapy applications in musculoskeletal, pediatrics, neurological, cardio-respiratory, and sports conditions, the specialists are less mindful of late advances in physiotherapy practice and its application in the field of women health and geriatric conditions. Further, it claimed the low rate of awareness of physical therapist role in intensive care, cardiopulmonary care, orthotic and prosthetic prescription ${ }^{15}$.

Keefe FJ, Main CJ, George SZ. Advancing psychologically informed practice for patients with persistent musculoskeletal pain: promise, pitfalls, and solutions concluded that role of physical therapist among the senior doctors was considered remarkable in in-patient management and promotion of health as well as were aware of DPT programs ${ }^{16}$.

Maher Al Jadid et.al 2017, concluded in their study that there was immense majority of physicians who were aware of rehabilitation and 176 out of 200 stated that for rehabilitation there is a need of someone with expertise ${ }^{17}$. Additionally, some governments do not support and recognize physical therapist as professionals which adds another barrier to the awareness of the field ${ }^{18}$. In contrast to it, in many countries' physiotherapy enjoys an autonomous professional status $^{19}$. Also, the incorporation of evidence-based practice in the profession over decades has reshaped the profession, its knowledge and professional ethics, and is still ongoing ${ }^{20}$. In addition to it, the influence of continuing professional development has been observed in the field of physiotherapy for both practicing and non-practicing individuals ${ }^{21}$ Nonetheless, every accepted profession requires a certain accreditation however physiotherapy in some countries lacks this requirement of licensure that has been observed as another barrier in physical 
therapy awareness ${ }^{22}$. As stated in the study of Acharya et, al in Nepal the low awareness of physical therapy as a profession is due to a number of factors like, lack of curriculum, lack of staff, lack of job opportunities, lack of funding, mentoring and qualified instructors and also lack of ownership of the field ${ }^{23}$.

Further, clinical experts and allied health professionals assume a significant part in reference of patients for physiotherapy. From the study of Doshi et, al it is accepted that early reference and acknowledgment by clinical professional and mindfulness prompts better improvement and redemption of physiotherapy administrations which seems, by all accounts, to be underutilized as of now. Adding more to it, the reason observed for less referral has found to be deficient information of the field of physical therapy. Therefore, a need to direct the study among clinical and non-clinical experts to know the mindfulness, framework dysfunctions treated by physiotherapist and job of physiotherapy in managing illness is necessitated $^{23}$. It is now a crucial time that medical and non-medical professionals understand the importance and existence of physical therapy as a field that is shaped day to day with advances and evidence ${ }^{24}$.

Result of our study shows that on average Allied health professionals were aware about Physical Therapy. However, more researches are needed on this topic in order to provide more literature and to increase awareness and help change the perception regarding physical therapy scope in academic as well as in clinics.

\section{CONCLUSION}

It was concluded that majority of the participants were aware regarding the role of physiotherapy and its contribution towards the society however further researches should be conducted to explore related factors and different fields of rehabilitation among healthcare practitioners. Further continual sessions to improve the awareness of the health care professionals can lead to better referrals from them to the physiotherapy department and inclusion of physiotherapy to the regular treatment regimes.

\section{REFRENCES}

[1] Patel RD. Awareness about physiotherapy among high school students of anand district. International Journal for Innovative Research in Multidisciplinary field. 2015;1(1):4.

[2] Al-Sheibani A, Dboba MM, Astiata W, Alkamali $Y$. Education In Physiotherapy Department In The University Of Zawia In Libya. European Journal of Molecular \& Clinical Medicine. 2021 Feb 4;7(10):3606-11.

[3] Bezner JR. Promoting health and wellness: implications for physical therapist practice. Physical Therapy. 2015 Oct 1;95(10):1433-44.

[4] Bargaje PV, Bedekar NS, Rairikar S, Shyam A, Sancheti P. Perception of junior college students about Physiotherapy as a profession. Physiotherapy-The Journal of Indian Association of Physiotherapists. 2017 Jan 1;11(1):30.

[5] Abichandani D, Radia V. Awareness of various aspects of physiotherapy among medical residents. J Int Med Res. 2015;4(10):1460-5.

[6] Al-Eisa ES, Al-Hoqail $\mathrm{H}, \mathrm{Al}$-Rushud AS, Al-Harthi A, Al-Mass B, Al-Harbi BM, Al-Azzaz $S$, Alghadir $A H$, lqbal ZA. Awareness, perceptions and beliefs about physiotherapy held by physicians working in Saudi Arabia: a cross-sectional study. Journal of physical therapy science. 2016;28(12):3435-9.

[7] Alshewaier SA. Developing a standardised preoperative 
physiotherapy programme to improve the outcomes of patients undergoing anterior cruciate ligament reconstruction in Riyadh (KSA) (Doctoral dissertation, Manchester Metropolitan University).

[8] Alyahya F, Algarzaie K, Alsubeh Y, Khounganian R. Awareness of ergonomics \& work-related musculoskeletal disorders among dental professionals and students in Riyadh, Saudi Arabia. Journal of physical therapy science. 2018;30(6):770-6.

[9] Moffatt F, Goodwin R, Hendrick P. Physiotherapy-as-first-point-ofcontact-service for patients with musculoskeletal complaints: understanding the challenges of implementation. Primary health care research \& development. 2018 Mar;19(2):121-30.

[10] Denton C, Meerburg J, van der Rots $M$, Beenhakker JC. THE CHALLENGE FOR THE FUTURE OF PHYSIOTHERAPY. physiotherapy. 1982 Dec;38(4):83.

[11] Sarikaya S, Kurtaiş Y, Soyupek F, Hafiz $M$, Sarp Ü. The awareness of physicians and allied health professionals about cardiopulmonary rehabilitation: A cross-sectional survey study.

[12] Levenhagen K, Davies C, Perdomo M, Ryans K, Gilchrist L. Diagnosis of upper quadrant IFymphedema secondary to cancer: clinical practice guideline from the Oncology Section of the American Physical Therapy Association. Physical therapy. 2017 Jul 1;97(7):729-45.

[13] D. C. G. C. S., October 2013. AWARENESS OF PHYSICAL THERAPY REHABILITATION FOR BREAST CANCER RELATED LYMPHEDEMA AMONG MEDICAL ONCOLOGY TEAM - A SURVEY. International Journal of Physiotherapy and Research, 1(4), pp. 161 - 165.

[14] Khedekar S, Shimpi AP, Shyam A, Sancheti P. Use of art as therapeutic intervention for enhancement of hand function in patients with rheumatoid arthritis: A pilot study. Indian Journal of Rheumatology. 2017 Apr 1;12(2):94.

[15] Shimpi A, Writer $H$, Shyam A, Dabadghav R. Role of physiotherapy in India-A cross-sectional survey to study the awareness and perspective among referring doctors. Journal of Medical Thesis. 2014 May;2(2):18-22.

[16] Keefe FJ, Main CJ, George SZ. Advancing psychologically informed practice for patients with persistent musculoskeletal pain: promise, pitfalls, and solutions. Physical therapy. 2018 May 1;98(5):398-407.

[17] Maher Al Jadid, M. S. A. N. M. A. H. A. A. H. R. A. A. S. A. a. S. F., 2017. Physician Awareness of Phys- ical Medicine and Rehabilita- tion: A Cross-Sectional Study. HSOA Journal of Physical Medicine, Rehabilitation \& Disabilities, 4(1), pp. 1-5.

[18] Armstrong J, Ager A. Physiotherapy in Afghanistan: an analysis of current challenges. Disability and Rehabilitation. 2006 Jan 1;28(5):31522.

[19] Kell C, Owen G. Physiotherapy as a profession: Where are we now?. International journal of therapy and rehabilitation. 2008 Apr;15(4):158-67.

[20] Higgs JO, HUNT A, HIGGS C, NEUBAUER D. Physiotherapy education in the changing international healthcare and educational contexts. Advances in Physiotherapy. 1999 Jan 1;1(1):17-26.

[21] French HP, Dowds J. An overview of continuing professional development in physiotherapy. Physiotherapy. 2008 Sep 1;94(3):190-7.

[22] Acharya RS, Adhikar SP, Oraibi SA, Baidya S. Challenges and future development of physiotherapy education in Nepal. International Journal of Current Research and Review. 2015 Jul;7(13):35. 
[23] Doshi D, Jiandani M, Gadgil R, Shetty

$N$. Physiotherapy awareness in medical and non medical population: A social media survey. Int J Physiother Res. 2017;5(2):1971-5.

[24] Pattanshetty R, Metgud DC. Awareness of physiotherapy among other health professionals in India: Current scenario. Indian Journal of Physical Therapy and Research. 2019 Jul 1;1(2):69. 